\title{
Carelign: A Novel Handoff System for Medical and Surgical Consultants
}

\author{
Brian Michael Shafer, MD ${ }^{1}$ Thomasine Gorry, MD ${ }^{1} \quad$ Paul Tapino, MD ${ }^{1} \quad$ Subha Airan-Javia, MD² \\ ${ }^{1}$ Department of Ophthalmology, Scheie Eye Institute, University of \\ Pennsylvania Health System, Philadelphia, Pennsylvania \\ 2 Department of Internal Medicine, University of Pennsylvania Health \\ System, Philadelphia, Pennsylvania \\ Address for correspondence Brian Michael Shafer, MD, Department \\ of Ophthalmology, Scheie Eye Institute, University of Pennsylvania, 51 \\ North 39th Street, Philadelphia, PA 19104 \\ (e-mail: Brian.Shafer@uphs.upenn.edu). \\ J Acad Ophthalmol 2020;12:e63-e66.
}

\begin{abstract}
Keywords

- handoff

- consultant

- inpatient ophthalmology

- residency

Background Patient handoffs are ubiquitous in hospital settings. Historically, formal handoffs of patient information have been conducted in the inpatient setting mainly by primary teams, as opposed to medical and surgical consultants. Carelign is a software developed by the University of Pennsylvania Health System to function as an interdisciplinary, patient-centered handoff. While mainly utilized by primary teams for work management and transitions, it has been enhanced to include specialty consultant handoff functionality.

Objective The aim of this study is to determine whether using Carelign for consultant handoffs improves clinical handoffs in comparison to the prior handoff system (a custom-built handoff report within the electronic health record) used by the Department of Ophthalmology at Penn Presbyterian Medical Center.

Methods A 7-item questionnaire assessing the effectiveness, efficiency, accessibility, reliability, communication, and security of the handoff using a 1 to 5 scale was distributed to residents prior to and 6 months subsequent to the implementation of Carelign.

Results Users reported a statistically significant increase in Health Insurance Portability and Accountability Act (HIPPA)-compliance (44 vs. $100 \%, p<0.0001)$ and ability to communicate with primary teams ( 38 vs. $70 \%, p=0.019$ ) after implementation of Carelign. There was a trend toward significance with ease of accessing information after switching to Carelign ( 67 vs. $85 \%, p=0.185$ ). There was no statistically significant difference in effectiveness, efficiency, accessibility from home, or reliability of information on handoff after converting to the new system.

Conclusion Carelign is perceived to be an effective tool that can be used by consulting providers to ensure HIPPA-compliance and the ability to communicate with primary teams without sacrificing effectiveness, efficiency, accessibility, or reliability.
\end{abstract}

Effective patient handoffs help reduce preventable errors and improve coordination of clinical care. ${ }^{1}$ For acute care providers, such as Hospitalists, optimizing patient handoffs to prevent adverse events and near misses has been a wellestablished safety priority, ${ }^{2-4}$ with hospitalists historically leading such initiatives. As a result of these efforts, there are a myriad of computer-based handoff systems available to providers. $^{5}$

In 2006, the joint commission issued a National Patient Safety Goal which mandates providers to utilize a "standardized approach for handoff communications." on studies demonstrating that lack of standardization can lead received

December 22, 2019

accepted

April 13, 2020
DOI https://doi.org/

$10.1055 / \mathrm{s}-0040-1712173$. ISSN 2475-4757.
Copyright (c) 2020 by Thieme Medical Publishers, Inc., 333 Seventh Avenue, New York, NY 10001, USA. Tel: +1(212) 760-0888.
License terms

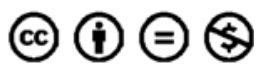


to adverse events. ${ }^{7}$ In addition to standardization, handoff systems must contain reliable information that is easily accessible and editable by providers. Of course, these systems must also be Health Insurance Portability and Accountability Act (HIPPA) compliant. Specifically, HIPPA-compliance mandates that Personally Identifiable Information is protected from fraud and theft and remains appropriately private.

There is a growing recognition of the importance of handoffs for medical and surgical consultants in addition to primary inpatient teams. In academic centers, the consultant provider often changes daily. Given the frequency of transitions, there is an elevated risk of issues with discontinuity. ${ }^{8}$ Therefore, there is a significant need for high-quality handoff systems inclusive of consultant care to ensure cohesive patient management.

Carelign is a software developed by the University of Pennsylvania that has been utilized by primary teams to exchange key information during care transitions as well as to manage day-to-day work. The application has recently been enhanced to improve its usability for consultant handoffs. Carelign is a mobile web application that provides clinicians with real-time clinical data at the point of care, coupled with robust, team-based handoff tools to improve communication, clinician experience, and patient care. As part of this educational innovation, additional functionality was added to the software to improve consultant handoff workflow such as listbased access to consultant handoff text and shortcut text expansions to standardize handoff content and more.

The goal of this quality improvement study was to determine if the implementation of Carelign as a consultant handoff system would improve the efficiency, effectiveness, reliability, accessibility, HIPPA-compliance of inpatient handoffs as well as improve the ability of consultants to communicate with primary teams for the University of Pennsylvania Department of Ophthalmology at a Penn Presbyterian Medical Center.

\section{Methods}

All 15 ophthalmology residents at the University of Pennsylvania were asked to take part in the study. Of the five first-year residents, four were included in the study with the fifth resident being excluded due to participation as a study investigator. In total, 14 potential subjects were asked to take part in the study. All study protocols were performed with accordance to the University of Pennsylvania's Institutional Review Board and with adherence to the Declaration of Helsinki.

A survey with seven questions, each with a 5-point Likert scale from strongly disagree to strongly agree was created. The questions assessed trainee perception of the handoff system being used at the time they were completing the survey. Each survey question was supplemented with a paragraph explaining the question. "Effective" was described to mean that the resident could input all pertinent information including patient name, hospital location, problem, dates seen, treatment plan, and task list. "Efficient" was described to mean that accessing and inputting data were quick and not cumbersome. "Communication with primary teams" was described as the ability to transmit sign-out information with the primary providers without external communication. "Accessible" meant that the system was able to be accessed quickly and efficiently without too many steps. "HIPPA-compliant" meant that the information stored in the handoff system was felt to be secure and unbreachable. "Able to access from home" was described to mean that the system could be accessed from a home device such as phone or computer. "Reliable" meant that the information included in the sign-out was felt to be accurate and complete.

The questionnaire was first distributed to the subjects in July of 2017. At that time, the handoff system consisted of a computer document that required manual input of patient information and tasks to be completed. The document was then sent as an encrypted email to each first year resident taking call at a single center at the end of each day. Whenever patient information changed or a new consult was placed, the document would have to be downloaded to a computer, edited, emailed to the group, and then deleted from the computer in an attempt to comply with HIPPA regulations. This document was sent only to ophthalmology residents, and therefore, there was no interaction with the primary teams.

The handoff system was converted to Carelign in August of 2017. All junior residents responsible for primary call used the integrated handoff system exclusively for 6 months. Only residents who had exclusively used the system for a minimum of 6 months were included in the final survey. At that point, the original questionnaire was redistributed and filled out by the four first-year study participants.

Analysis of the survey entailed tallying the points in each category and dividing by the total points available to generate a percentage. Statistical analysis using a simple $t$-test was performed to evaluate for statistical significance.

\section{Results}

Of the 14 eligible participants, $78.5 \%$ (11/14) completed the initial survey regarding the handoff system in effect in July of 2017. A total of $100 \%$ (4/4) of the eligible first year ophthalmology residents completed the final survey 6 months after the implementation of Carelign.

There was a statistically significant increase mean score regarding HIPPA-compliance and communication with the primary team after converting to Carelign (-Table $\mathbf{1}$ ). There was a trend toward significance with a mean increase in accessibility of information after switching to Carelign. There was no statistically significant difference with regard to handoff system effectiveness, efficiency, reliability of information, or accessibility from home.

\section{Discussion}

Throughout the United States, hospital inpatients are cared for by multidisciplinary teams including medical and surgical consultants. Although the structure of the consulting service is determined by individual departments, invariably there are handoffs between providers. Given that handoffs are the most precarious time for patient information to be lost, ${ }^{1-4}$ it is essential that each department share a common tool for clinical handoff. 
Table 1 Response to questionnaire before and after switching to Carelign

\begin{tabular}{|l|l|l|l|}
\hline & $\begin{array}{l}\text { Before } \\
\text { Carelign }\end{array}$ & $\begin{array}{l}\text { After } \\
\text { Carelign }\end{array}$ & $p$-Value \\
\hline $\begin{array}{l}\text { Handoff system } \\
\text { is effective }\end{array}$ & $3.64 \pm 1.12$ & $4.25 \pm 0.50$ & 0.318 \\
\hline $\begin{array}{l}\text { Handoff system } \\
\text { is efficient }\end{array}$ & $3.36 \pm 0.81$ & $3.25 \pm 1.26$ & 0.838 \\
\hline $\begin{array}{l}\text { Communication } \\
\text { with primary team }\end{array}$ & $1.91 \pm 0.70$ & $3.50 \pm 0.58$ & 0.019 \\
\hline $\begin{array}{l}\text { Information is } \\
\text { easily accessible }\end{array}$ & $3.36 \pm 1.21$ & $4.25 \pm 0.50$ & 0.185 \\
\hline $\begin{array}{l}\text { Handoff is } \\
\text { HIPPA-secure }\end{array}$ & $2.18 \pm 0.87$ & $5.00 \pm 0.00$ & $<0.0001$ \\
\hline $\begin{array}{l}\text { Handoff is } \\
\text { accessible } \\
\text { from home }\end{array}$ & $4.09 \pm 1.14$ & $4.25 \pm 0.50$ & 0.795 \\
\hline $\begin{array}{l}\text { Information on } \\
\text { handoff is reliable }\end{array}$ & $3.82 \pm 0.75$ & $3.50 \pm 1.91$ & 0.638 \\
\hline
\end{tabular}

Abbreviation: HIPPA, Health Insurance Portability and Accountability Act. Note: Mean scores with standard deviation.

In our study, we have demonstrated a novel system for consulting providers to communicate both internally within the department but also externally to other providers. This benefit, in addition to HIPPA-compliance, came without sacrificing important factors such as effectiveness, efficiency, accessibility, and reliability.

Although the data do not demonstrate a clear improvement in effectiveness, efficiency, accessibility, or reliability, we believe more of an improvement would have been detected if the survey were given more than 6 months after implementation. In the 12 months since this study, all residents have commented on Carelign being superior in all of the metrics measured in the study. Compared with the previous system of writing a document and emailing it nightly, residents feel that there is no longer any risk of private information being saved to a computer desktop. Additionally, residents have commented that they appreciate the ability to have all information centralized on a computer system that they can access from home. Further, residents no longer need to input data such as room numbers which may change frequently.

Importantly, feedback from users has revealed benefits from using Carelign not initially captured with our survey. Multiple users have reported the new tool has improved their day-to-day experience and decreased their time doing "scut work." In the era of "physician burnout," optimizing quality clinical time and decreasing unnecessary work-place frustrations is essential. Additionally, Carelign allows for more timely direct communication with the primary team, therefore leading to faster decision-making, less wasted time, and less frustrations for both the consult and primary teams. Future studies are warranted to identify whether the use of Carelign may decrease burnout.

Modern legislation requires that the exchange of all medical information remain HIPPA compliant. The national standard for handoffs is paper lists-which are inherently not HIPAA compliant-as they can be left in unsecured locations, inappropriate saved on desktops and storage devices, or found by individuals not part of the care team. With an electronic handoff built on a HIPAA compliant platform, accessible from mobile devices as well as all health system computers, the dependence on paper reports is eliminated, thereby significantly reducing the risk of HIPAA violations.

To increase transparency between clinical teams as well as to comply with the Joint Commission's National Patient Safety Goal mandating standardization within handoff systems, there is no personalization functionality within Carelign. There is, however, the ability to filter views to accommodate specialty workflow as well as to include text replacements specific to a clinical specialty. Additionally, users are able to request modifications to improve the system. After initial implementation of the program within the ophthalmology department, the users requested several features to augment their workflow using Carelign. Within weeks, the modifications were implemented. This responsiveness and agile approach to software design and maintenance has greatly improved our ability to effectively use a new software for a complicated workflow.

There are several limitations to our study. First, the follow-up survey was completed just 6 months after implementation of the new handoff system. This may not have been enough time for all residents to become familiar with Carelign. Additionally, since only first year ophthalmology residents see inpatients at Penn Presbyterian Medical Center, there was a small sample size of four subjects. With a larger sample size, it is possible that some of the data would have achieved statistical significance. Given these limitations, future studies with larger cohorts are warranted.

Carelign has been a welcomed change in handoff at the University of Pennsylvania within the Department of Ophthalmology, and it is likely that the system will only continue to improve.

\section{Conclusion}

Carelign is perceived to be an effective, patient centered, interdisciplinary handoff tool that can be used by consulting providers to improve HIPPA-compliance and the ability to communicate with primary teams without sacrificing effectiveness, efficiency, accessibility, or reliability.

Funding

None

Conflict of Interest

Subha Airan-Javia is cofounder and chief medical officer of McCoy Health LLC.

\section{References}

1 Solet DJ, Norvell JM, Rutan GH, Frankel RM. Lost in translation: challenges and opportunities in physician-to-physician communication during patient handoffs. Acad Med 2005;80(12):1094-1099

2 Singh H, Thomas EJ, Petersen LA, Studdert DM. Medical errors involving trainees: a study of closed malpractice claims from 5 insurers. Arch Intern Med 2007;167(19):2030-2036 
3 Arora V, Johnson J, Lovinger D, Humphrey HJ, Meltzer DO. Communication failures in patient sign-out and suggestions for improvement: a critical incident analysis. Qual Saf Health Care 2005;14(06):401-407

4 Horwitz LI, Moin T, Krumholz HM, Wang L, Bradley EH. Consequences of inadequate sign-out for patient care. Arch Intern Med 2008;168(16):1755-1760

5 Arora VM, Manjarrez E, Dressler DD, Basaviah P, Halasyamani L, Kripalani S. Hospitalist handoffs: a systematic review and task force recommendations. J Hosp Med 2009;4(07):433-440
6 Catalano K. JCAHO'S national patient safety goals 2006. J Perianesth Nurs 2006;21(01):6-11

7 Patterson ES, Roth EM, Woods DD, Chow R, Gomes JO. Handoff strategies in settings with high consequences for failure: lessons for health care operations. Int J Qual Health Care 2004;16(02): 125-132

8 Vidyarthi AR, Arora V, Schnipper JL, Wall SD, Wachter RM. Managing discontinuity in academic medical centers: strategies for a safe and effective resident sign-out. J Hosp Med 2006;1(04): 257-266 